\title{
Prevalence and Intensity of Infection of Gastro-Intestinal Parasites in Babadjou, West Region of Cameroon
}

\author{
V. Khan Payne*, Lontuo F. Robertine, Ngangnang G. Romeo, Megwi Leonelle, Mbong Erica, \\ Yamssi Cedric, Bamou Roland, Mpoame Mbida
}

Department of Animal Biology, Faculty of Science, University of Dschang, Dschang, Cameroon

Email address:

vk.payne@yahoo.com (V. K. Payne)

${ }^{*}$ Corresponding author

\section{To cite this article:}

V. Khan Payne, Lontuo F. Robertine, Ngangnang G. Romeo, Megwi Leonelle, Mbong Erica, Yamssi Cedric, Bamou Roland, Mpoame Mbida. Prevalence and Intensity of Infection of Gastro-Intestinal Parasites in Babadjou, West Region of Cameroon. International Journal of Clinical and Experimental Medical Sciences. Vol. 3, No. 2, 2017, pp. 14-22. doi: 10.11648/j.ijcems.20170302.11

Received: April 3, 2017; Accepted: April 17, 2017; Published: May 10, 2017

\begin{abstract}
Helminth infections, such as Ascaris lumbricoides, Trichuris trichiura and Hookworms are major public health concerns. The aim of this study was to evaluate the prevalence and intensity of infection of gastro-intestinal helminthiasis in Babadjou. Qualitative and quantitative analyses were carried out on eight hundred and twenty five (825) stool samples collected from residents using the simple centrifugal flotation and McMaster count technique respectively. Out of the 825 samples examined, $70(8.5 \%)$ were infected with at least one helminth parasite with prevalence and intensities of infection of $4.4 \%$ and $2594.44 \pm 3897.17$ for A. lumbricoides, $4.2 \%$ and $72.86 \pm 110.04$ for $T$. trichiura, $1.9 \%$ and $83.33 \pm 72.37$ for Hookworms and $0.2 \%$ and $50 \pm 00$ for Capillaria hepatica respectively. Males (13.8\%) were more infected than females (8.6\%). The prevalence of A. lumbricoides and T. trichiura vary significantly with age groups with those of 1-10 years taking the lead (17.9\%). The prevalence between the three educational levels differed significantly $(\mathrm{P}<0.05)$ for $A$. lumbricoides, $T$. trichiura and Hookworm where those from the primary level were most infected $(28.6 \%)$. The locality of Bamedji showed very high prevalences of $A$. lumbricoides $(35.7 \%)$ and $T$. trichiura $(17.9 \%)$ with significant differences as well. From the different occupations involved in the current study, students harboured all the four nematodes encountered. Cases of double and triple infections were recorded with A. lumbricoides $+T$. trichiura (2.4\%) being the highest and A. lumbricoides $+T$. trichiura + Hookworms $(0.2 \%)$ the only triple infection registered. According to fecal concentration of eggs, $77.01 \%$ of infections were light infections, 3.44\% moderate and $19.54 \%$ heavy infections. Only A. lumbricoides had heavy infections while all Hookworm infections were light. The results found on this study show that, it is important to control and prevent gastrointestinal helminths in and around Babadjou.
\end{abstract}

Keywords: Gastro-intestinal Helminths, Prevalence, Intensity, Babadjou, West Region, Cameroon

\section{Introduction}

Parasitic infections constitute a major health problem in tropical and subtropical zones where climatic conditions like temperature and humidity, lack of hygiene, poverty, sociocultural habits and demographic parameters favour their development ${ }^{1}$. The World Health Organization (WHO) estimates over 2 billion people in the world living with these parasitic infections where school age children and women at the age of procreation are the most infected ${ }^{2}$.

These parasitic diseases kill more than 155,000 thousand people per year with $97 \%$ of these deaths occurring in the developing countries ${ }^{3}$. Intestinal helminthiasis among these parasitic infections are the most common infections occurring throughout the developing world ${ }^{4}$ with 89.9 million school age children infected in Sub Saharan Africa ${ }^{5}$. In 2004, a report from the Cameroonian Public health Secretary of state revealed 16.1 million inhabitants in Cameroon with more than 10 million infected with helminthiasis ${ }^{6}$. The commonest and well known of these helminthiasis are Ascariasis caused by Ascaris lumbricoides affecting 1.5 billion people, Hookworms (Ancylostoma duodenale and Necator americanus) affecting 1 billion and trichuriasis due to Trichuris trichiura affecting 800 
million people throughout the world ${ }^{7}$.

Given that there is limited information in Babadjou regarding the occurrence of STHs, our main objective was to determine the prevalence and intensity of infection of helminthiasis among residents in Babadjou.

\section{Materials and Methods}

\subsection{Area of Study}

This study was carried out in Babadjou situated along the Bafoussam-Bamenda (National $\mathrm{n}^{\circ} 6$ ) transect in the Bamboutos Division with a surface area of $250 \mathrm{~km}^{2}$ and a population of 50.000 inhabitants. Its geographical position or coordinates are $5^{\circ} 40^{\prime}$ North, $10^{\circ} 12^{\prime}$ East. Temperatures are relatively low with intense rainfall. The dry season runs from December-April and the rainy season from May- November. Babadjou is bordered in the North by the Bamevuh and Bammock villages of the South West Region, in the East by the Pinying village of the North West region, in the West by the Balatchi village and in the South by the Bamessingue village both of the Western Region ${ }^{8}$.

\subsection{Ethical Clearance}

To carry out this research, an ethical clearance was obtained from the National Ethics Committee of Cameroon, in order to ensure consent and confidentiality of the participants.

\subsection{Study Population}

The subjects were 825 from 14 different quarters of Babadjou randomly selected between October and December 2014. This study population was comprised of both children and adults aged from 2 to 98 years with a mean age of $22.8 \pm$ 19.9 years. Three educational levels were represented (Nursery, Primary and Secondary levels of education). The study population was made up of $486(59 \%)$ females and 339 $(41 \%)$ males with a majority being students.

\subsection{Parasitological Examination}

Coprologic analysis was done to have a quantitative and qualitative appreciation of the prevalence of infection of the parasites. For the qualitative analysis, faeces were analysed by the double-centrifugal flotation technique using saturated sodium chloride solution (concerntration: 6.84M). For quantitative analysis or determination of the number of eggs per gram of faeces, the Mc Master technique described by Thienpont et al., ${ }^{9}$ was used.

\subsection{Statistical Analysis}

Data was stored in a Microsoft Excel spread sheet and then exported to SPSS (Statistical Package for Social Science, v 20) software for analysis. Summary statistics were generated using the same software. For the purpose of modeling these data, explanatory variables were first explored for associations between parasites using $\chi^{2}$ test. The prevalence of helminth parasites were compared between demographic parameters using the chi square test. They were all tested at $5 \%$ significance level.

\section{Results}

\subsection{Prevalence of Infection Among Residents}

Out of the eight hundred and twenty five (825) stool samples examined, $70(8.5 \%)$ were infected with at least one parasitic helminth (table 1). Four different helminths were recorded, all of which were nematodes. These nematodes included: Ascaris lumbricoides, Trichuris trichiura, Hookworm and Capillaria hepatica with specific prevalences of $4.4 \%$ (36 infected), $4.2 \%$ (35 infected), $1.9 \%$ (16 infected) and $0.2 \%$ ( 2 infected) respectively.

Table 1. The overall percentage of infected and uninfected individuals.

\begin{tabular}{lll}
\hline Parasitic status & No. of individuals & Frequency (\%) \\
\hline Infected with at least one parasite & 70 & 8.5 \\
Not infected & 755 & 91.5 \\
Total & 825 & 100.0 \\
\hline
\end{tabular}

Generally, both sexes were infected with all the above stated nematodes. Out of the 486 females examined, 42 (8.6\%) harboured parasites while $47(13.8 \%)$ of the 339 males were tested positive for these nematodes as shown on table 2 below. It can be noted that the overall prevalence was higher in males than in females with no significant difference $(\mathrm{P}>0.05)$. Ascarislumbricoides $(5.0 \%)$, Trichuris trichiura (5.6\%) and Hookworm (2.9\%) infections were slightly higher in males while in females, it was $3.9 \%, 3.3 \%$, and $1.2 \%$ respectively. Capillaria hepatica had no difference in prevalence between both sexes.

Table 2. Prevalence of parasitic helminths with participant gender.

\begin{tabular}{llllll}
\hline \multicolumn{1}{l}{ Gender } & & & \\
\hline Parasitic helminths & Females N (\%) & Males N (\%) & Total N (\%) & $\boldsymbol{\chi}^{2}$ & Df \\
\hline Ascaris lumbricoides & $19(3.9)^{*}$ & $17(5.0)$ & $36(4.4)$ & 0.575 & 1 \\
Trichuris trichiura & $16(3.3)$ & $19(5.6)$ & $35(4.2)$ & 2.608 & 1 \\
Capillaria hepatica & $1(0.2)$ & $1(0.3)$ & $2(0.2)$ & 0.065 & 1 \\
Hookworm & $6(1.2)$ & $10(2.9)$ & $16(1.9)$ & 3.074 & 0.106 \\
Total & $42(8.6)$ & $47(13.8)$ & $87(10.5)$ & & \\
\hline
\end{tabular}

*: Number of positive cases and prevalence $(\%)$ in bracket

It can be noticed on table 3 below that Hookworm infections were present in all the age groups except the last age group. The prevalence of parasitic helminthiasis was highest in children from 1 to 10 years with an overall 
prevalence of $17.9 \%$. In this group, A. lumbricoides, $T$. trichiura, Hookworm and C. hepatica infections had specific prevalences of $7.6 \%, 7.2 \%, 2.9 \%$ and $0.4 \%$ respectively. This was followed by those of the second group who were aged from 11 to 20 years with $A$. lumbricoides $(4.9 \%)$ and $T$. trichiura $(4.5 \%)$ having the highest rates of occurrence. We can also note that prevalence gradually decreased with increasing age. The least infections occurred in the $51-60$ age group with only $1(2.4 \%)$ Hookworm infection while it was completely absent in those of 60 years and above. The prevalence of $A$. lumbricoides and T. trichiura had significant differences between the age groups $(\mathrm{P}<0.05)$.

Table 3. The Prevalence of helminth infections amongst age groups.

\begin{tabular}{llllll}
\hline \multicolumn{7}{l}{ Parasitic helminths } & & & \\
\hline Age group (years) & Ascaris lumbricoides N (\%) & Trichuris trichiura N (\%) & Capillaria hepatica N (\%) & Hookworm N (\%) & Total N (\%) \\
\hline $2-10$ & $21(7.6)$ & $20(7.2)$ & $1(0.4)$ & $8(2.9)$ & $50(17.9)$ \\
$11-20$ & $12(4.9)$ & $11(4.5)$ & & $3(1.2)$ & $26(10.5)$ \\
$21-30$ & $1(1.2)$ & $2(2.4)$ & & $2(2.4)$ & $5(6.0)$ \\
$31-40$ & $2(3.1)$ & $1(1.6)$ & $1(1.9)$ & $1(1.6)$ & $4(6.25)$ \\
$41-50$ & & $1(1.9)$ & & $1(1.9)$ & $3(5.6)$ \\
$51-60$ & & $2(0.2)$ & $1(2.4)$ & $1(2.4)$ \\
$>60$ & $36(4.4)$ & $35(4.2)$ & & & $16(1.9)$ \\
Total & 16.18 & 13.01 & & 3.343 & $89(10.78)$ \\
$\chi^{2}$ & 0.013 & 0.043 & & 0.765 & \\
p-value & & & & \\
\hline
\end{tabular}

*: Number of positive cases and prevalence (\%) in bracket

The prevalence between nursery, primary and secondary school children differ significantly $(\mathrm{P}<0.05)$. Those from the primary level were the most infected $(28.6 \%)$ against a prevalence of $17.3 \%$ from the secondary level of education.
Only 2 participants came from the nursery level of which none of them was infected. We also observed a prevalence of $2.9 \%$ from those who did not provide any information on their educational status (Table 4).

Table 4. The prevalence of parasitic helminths according to level of education.

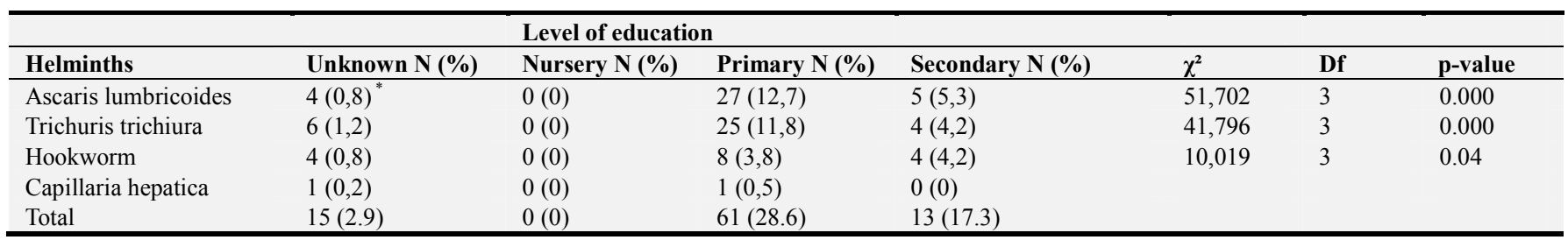

*: Number of positive cases and prevalence $(\%)$ in bracket

Out of the 14 quarters involved in our study, at least one parasitic helminth was identified in each of them except Nkameleh which harboured no parasites. Bamedji showed very high prevalences of A. lumbricoides (35.7\%) and T. trichiura (17.9\%) with significant differences $(\mathrm{P}<0.05)$ between the localities as shown on table 5 below.

Table 5. The prevalence of parasitic helminths among localities.

\begin{tabular}{|c|c|c|c|c|c|}
\hline \multirow[b]{2}{*}{ Localities } & \multirow[b]{2}{*}{ Ascaris lumbricoides N (\%) } & \multicolumn{3}{|l|}{ Parasitic helminths } & \multirow{2}{*}{ Total } \\
\hline & & Trichuris trichiura $\mathbf{N}(\%)$ & Hookworm N (\%) & Capillaria hepatica $\mathbf{N}(\%)$ & \\
\hline Balepo & $2(3.0)^{*}$ & $1(1.5)$ & $0(0)$ & & $3(6.06)$ \\
\hline Bamedji & $10(35.7)$ & $5(17.9)$ & $0(0)$ & & $15(53.57)$ \\
\hline Bamedjingha & $2(1.2)$ & $7(4.3)$ & $5(3.0)$ & & $14(8.53)$ \\
\hline Bamejuih & $1(0.7)$ & $3(2.0)$ & $4(2.6)$ & $1(0.7)$ & $9(5.96)$ \\
\hline King place & $5(10.6)$ & $4(5.5)$ & $1(2.1)$ & & $10(21.27)$ \\
\hline Metongfeu & $0(0)$ & $0(0)$ & $1(3.1)$ & & $1(3.10)$ \\
\hline Ngagong & $2(3.4)$ & $5(8.5)$ & $1(1.7)$ & & $8(13.55)$ \\
\hline Ngindah & $1(6.2)$ & $1(6.2)$ & $0(0)$ & & $2(12.5)$ \\
\hline Ngon-yeuh & $1(3.3)$ & $3(10.0)$ & $0(0)$ & & $4(13.33)$ \\
\hline Nkameleh & $0(0)$ & $0(0)$ & $0(0)$ & & 0 \\
\hline Takang & $1(2.8)$ & $0(0)$ & $3(8.3)$ & $1(2.8)$ & $5(13.8)$ \\
\hline Tchimego & $0(0)$ & $1(3.6)$ & $0(0)$ & & $1(3.57)$ \\
\hline Toumaka & $5(9.4)$ & $2(3.8)$ & $1(1.9)$ & & $8(15.09)$ \\
\hline Zavion & $6(5.7)$ & $3(2.9)$ & $0(0)$ & & $9(8.57)$ \\
\hline Total & $36(4.4)$ & $35(4.2)$ & $16(1.9)$ & $2(0.2)$ & $89(10.78)$ \\
\hline$\chi^{2}$ & 86.984 & 27.203 & 15.062 & & \\
\hline p-value & 0.000 & 0.018 & 0.374 & & \\
\hline
\end{tabular}

*: Number of positive cases and prevalence (\%) in bracket 
Looking at table 6 , one can easily notice the complete absence of infection in most of the occupations yet, students harboured all the 4 nematodes identified during the course of this study. The prevalence of $A$. lumbricoides was relatively high in gardeners $(11.1 \%)$ followed by students $(8.5 \%)$ and house wives (2.5). The pattern observed for T. trichiura was higher in bike riders (7.7\%), followed by students $(6.7 \%)$ and farmers $(4.8 \%)$. The trend observed for Hookworm was higher in teachers $(25 \%)$ and $C$. hepatica infections recorded high prevalence in farmers. However, all these differences were not statitically significant $(\mathrm{P}>0.05)$.

Table 6. The prevalence of parasitic helminths according to occupation.

\begin{tabular}{|c|c|c|c|c|c|}
\hline & & Helminths & & & \\
\hline Profession & $\begin{array}{l}\text { Ascaris lumbricoides } \\
\text { N }(\%)\end{array}$ & $\begin{array}{l}\text { Trichuris trichiura } \\
\text { N }(\%)\end{array}$ & $\begin{array}{l}\text { Hookworm } \\
\text { N }(\%)\end{array}$ & $\begin{array}{l}\text { Capillaria hepatica } \\
\text { N }(\%)\end{array}$ & Total \\
\hline Farming & $1(1.6)^{*}$ & $3(4.8)$ & & $1(1.6)$ & $5(7.9)$ \\
\hline Student & $29(8.5)$ & $23(6.7)$ & $10(2.9)$ & $1(0.3)$ & $63(18.42)$ \\
\hline Teaching & & & $1(25)$ & & $1(25.0)$ \\
\hline House wife & $2(2.5)$ & $1(1.2)$ & $2(2.5)$ & & $5(6.5)$ \\
\hline Bike rider & & $1(7.7)$ & & & $1(7.6)$ \\
\hline Unknown & $3(1.1)$ & $7(2.5)$ & $3(1.1)$ & & $13(4.5)$ \\
\hline Total & $36(4.4)$ & $35(4.2)$ & $16(1.9)$ & $2(0.2)$ & 89 (10.78) \\
\hline$\chi^{2}$ & 26.209 & 11.447 & 16.466 & & \\
\hline p-value & 0.051 & 0.781 & 0.421 & & \\
\hline
\end{tabular}

*: Number of positive cases and prevalence $(\%)$ in bracket

In the course of our work, cases of parasitic associations were identified. Figure 1 below gives us a general overview of the different types of associations. Seven hundred and fifty five $(91.5 \%)$ individuals of the study population was tested negative of parasitic helminths. The highest infections were single infections with $53(6.4 \%)$ individuals followed by $15(1.8 \%)$ paraticipants with double infections. Only $2(0.2 \%)$ members of the study population harboured triple infections.

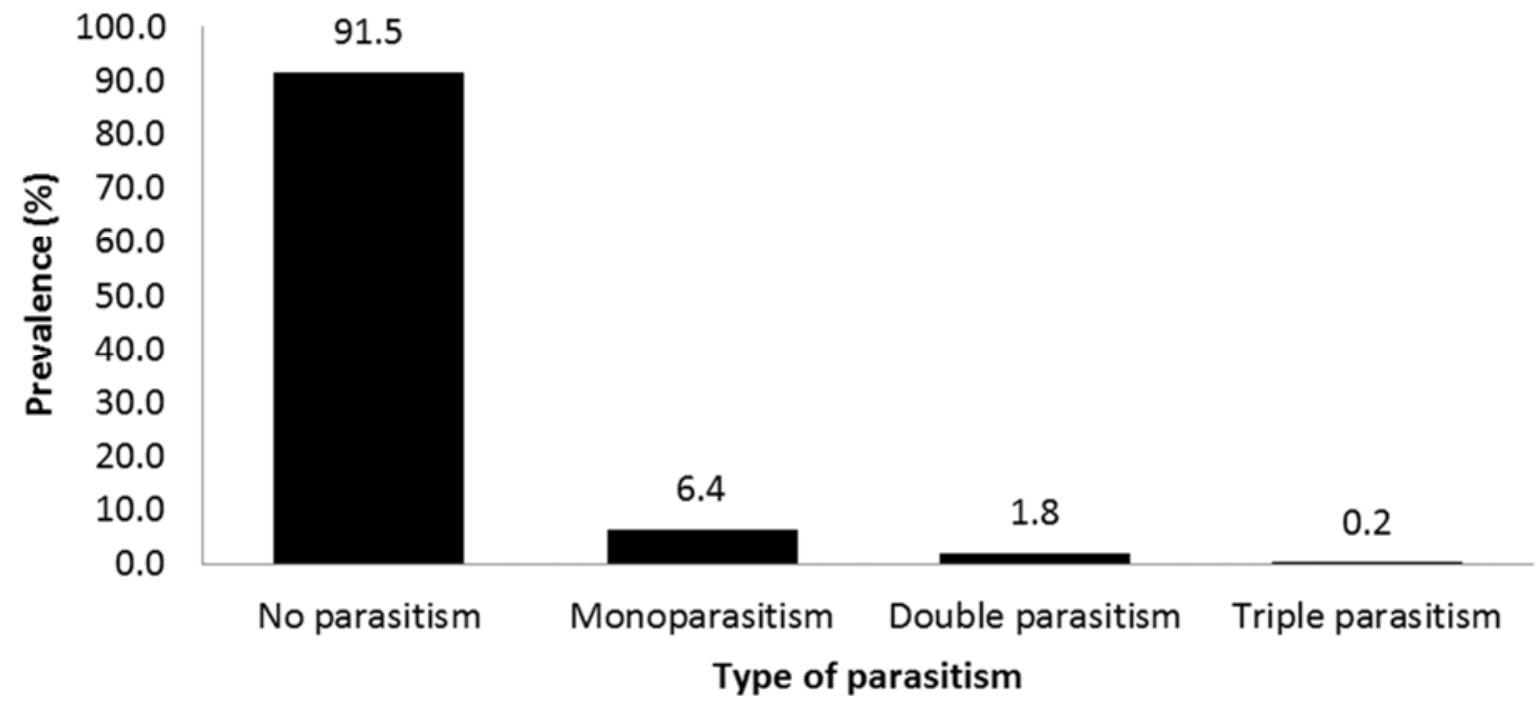

Figure 1. General presentation of parasitic associations.

The patterns of single, double and triple infections are shown in figure 2 below. A. lumbricoides and T. trichiura recorded the highest infection rates of $2.4 \%$ each amongst the single infections. Three types of double infections were observed with the association $A$. lumbricoides $+T$. trichiura being the most prevalent $(1.6 \%)$. The two other associations were those of $A$. lumbricoides + Hookworm and $C$. hepatica + Hookworm with a prevalence of $0.1 \%$ each. Only one triple infection was recorded. It was that of $A$. lumbricoides + T. trichiura + Hookworm with a prevalence of $0.2 \%$. 


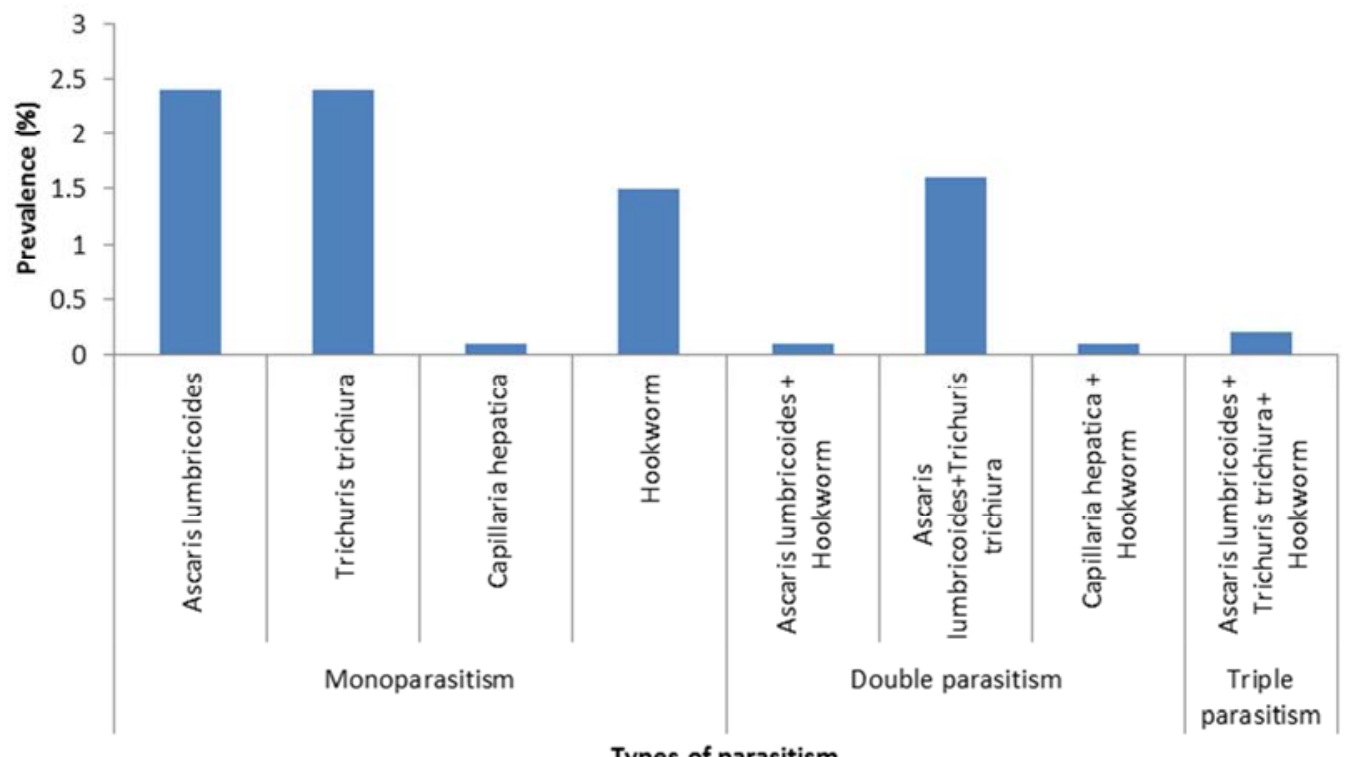

Figure 2. Prevalence of Single and mixed intestinal infections.

\subsection{Intensity of Infection (mean EPG) Among Residents}

The specific intensity of infection which is expressed in terms of mean concentration of eggs per gram (EPG) of faeces is shown on table 7. Out of the 825 stool samples examined, A. lumbricoides (2594.44 \pm 3897.174$)$ recorded the highest intensity of infection and $C$. hepatica the lowest $(50 \pm 00)$.

Table 7. Intensity of infection of the different helminth Parasites.

\begin{tabular}{lll}
\hline Parasites & No. Infected & Egg per gram $($ Mean \pm SD) \\
\hline Ascaris lumbricoides & $36^{*}$ & $2594.44 \pm 3897.174$ \\
Trichuris trichiura & 35 & $72.86 \pm 110.042$ \\
Hookworm & 16 & $83.33 \pm 72.375$ \\
Capillaria hepatica & 2 & $50 \pm 00$ \\
\hline
\end{tabular}

*No. infected: number of infected individuals

Based on the modified classification of geohelminths according to the faecal concentration of eggs by Deuyo (1997), table 8 was established. The pre-dominant intensity of infection was the light infection, where all Hookworm $(100 \%)$ infections were light infections. In general, $77.01 \%$ of infections were light infections, $3.44 \%$ moderate and $19.54 \%$ heavy infections. A. lumbricoides recorded $47.2 \%$ of heavy and light infections each and 5.6\% moderate. Light and moderate infections were also observed in T. trichiura with faecal concentrations of $97.1 \%$ and $2.9 \%$ respectively.

Table 8. Distribution according to faecal concentration of eggs.

\begin{tabular}{lllll}
\hline \multicolumn{4}{l}{ Intensity of infection } \\
\hline \multirow{2}{*}{ Parasites } & Light & Moderate & Heavy & Total \\
& $\mathbf{N ~ ( \% )}$ & $\mathbf{N}(\mathbf{\%})$ & $\mathbf{N ~ ( \% )}$ & $\mathbf{N}$ \\
\hline Ascaris lumbricoides & $17(47.2)^{*}$ & $2(5.6)$ & $17(47.2)$ & 36 \\
Trichuris trichiura & $34(97.1)$ & $1(2.9)$ & & 35 \\
Hookworm & $16(100)$ & & & 16 \\
Total & $67(77.01)$ & $3(3.44)$ & $17(19.54)$ & 87 \\
\hline
\end{tabular}

*: Number of positive cases and prevalence (\%) in bracket

\section{Discussion}

The main interest of this study was the prevalence and intensity of infection of helminthiasis in Babadjou in which the overall prevalence was found to be $8.5 \%$. This result corroborates that of Nougning ${ }^{1}$ in the localities of Bambui and Bambili North West Region of Cameroon who also recorded a prevalence of $8.5 \%$ among residents and the $8.2 \%$ obtained during a comparative study carried out in Wuyi and Laogang in the Republic of china ${ }^{10}$. It was relatively lower than the prevalence $(13.8 \%)$ reported by Ephrem et al. ${ }^{12}$ in Ethiopia and that of Wabo Poné et al., ${ }^{11}$ in Dschang, Western Region of Cameroon with a prevalence of $41.5 \%$. However, this overall prevalence is relatively high as compared to the $0.9 \%$ recorded by Zadock ${ }^{13}$ in the Same district. These differences may be explained by variations in socioeconomic status, regular de-worming campaigns, improvement in hygienic conditions, climatic and geographic conditions of the study area, as well as local endemicity of the study area for these particular parasites.

Four parasitic helminths were identified including $A$. lumbricoides, T. trichiura, Hookworms and C. hepatica with specific prevalences of $4.4 \%, 4.2 \%, 1.9 \%$ and $0.2 \%$ respectively. These results are similar to the values obtained by Nougning ${ }^{1}$ who recorded $4.37 \%$ in $A$. lumbricoides, $2.75 \%$ in T. trichiura and $1.57 \%$ in Hookworm infections but relatively low as compared to those registered in Dschang by Wabo Poné et al., ${ }^{11}$ (A. lumbricoides: 18\%, T. trichiura: $36 \%$, Hookworm: $11 \%$ ). These low specific rates may be due to public awareness, improvement of environmental sanitation and the national de-worming campaign for the fight against gastro-intestinal parasites. From the overall prevalence of intestinal helminths, $A$. lumbricoides comprised the most prevalent helminth parasite (4.4\%). This observation is consistent with the findings of Maffo Tatsinkou et al., ${ }^{14}$ in Dschang, Cameroon and Mohammed et 
al. ${ }^{15}$ in Ethopia who observed prevalences of $10.9 \%$ and $4.32 \%$ respectively. The high existence of this parasite among residents may be due to the resistant nature of the eggs to various environmental conditions. Also, these eggs are very adhesive and can easily stick to fruits, vegetables, flies and dust particles. The least prevalence was observed in C. hepatica $(0.2 \%)$. This is obvious because it is rarely found in humans and there are no endemic areas of infection with $C$. hepatica and human infection primarily results from zoonotic transmission or might have been the case of spurious infection ${ }^{16}$ with most of these infections found in children. This result corroborates that of Maffo ${ }^{17}$ who also observed a prevalence of $0.2 \%$. This can be explained by the fact that unembryonated eggs might have been ingested by individuals in which case they were harmlessly pass out in the faeces (spurious infection). Also, identification of $C$. hepatica eggs in the stool does not result from infection of the human host, but from ingestion of livers from infected animals by that host and the eggs will as well be harmlessly passed out in faeces ${ }^{18}$.

Among the various sexes, the males (13.8\%) harbour most of the helminth parasites than the females $(8.6 \%)$. These results are similar to those obtained in Cameroon by Maffo ${ }^{17}$ who recorded $21.53 \%$ and $17.84 \%$ in men and women respectively. This was also observed in Nigeria by Abelau et al. ${ }^{19}$ who recorded a higher prevalence in men $(23.6 \%)$ than in women $(20.2 \%)$ and by Akinseye et al., ${ }^{20}$. The higher prevalence in males recorded in this study may be due to the playing activities of male children. This could also be attributed to consistent exposure of the men to using of bare hands in carrying out farming and other laborious works without proper washing of the hands before eating. However, this difference though not statistically significant $(\mathrm{P}>0.05)$ was not in agreement with those observed in Nigeria by Biu and Kofur ${ }^{21}$ where females harboured more parasites than the males. The presence of these nematodes in both sexes is a clear indication that infection with helminth parasites is not sex dependent meanwhile Wabo Poné et al., ${ }^{11}$ observed a significant difference in the prevalence of helminth parasites between both sexes in Cameroon.

Furthermore, the findings of the current study also depicted that intestinal helminthic infections are more prevalent in younger children. The four helminth parasites occurred most in children of 2-10 years with A. lumbricoides and $T$. trichiura taking the lead. This result agrees with those carried out in Ethiopia by Gessessew et al., ${ }^{22}$ and Mohammed et al., ${ }^{15}$ and in Nigeria by Nmor et al., ${ }^{23}$. The second group with high infection rates was that of 11- 20 years. This remark was also in line with the report of Mohammed et al., ${ }^{15}$. The significant difference between prevalence in age groups might be attributed to the fact that younger children cannot properly keep their personal hygiene and their habit of crawling on contaminated soil exposes them to infection ${ }^{23}$. Also, the prevalence of helminthiasis decreased with increasing age with the last age group $(>60)$ harbouring no parasites at all. This is in accordance with the findings of Seleshi et al., ${ }^{24}$ who said it is probably due to the mature way adults handle personal hygiene; Susan 25 observed that immunity against intestinal helminths increases with age due to higher level of acquired immunity in the older ones. In contrast, these results did not agree with the report of Abelau et al., ${ }^{1}$ in Nigeria who found helminth parasites to be most common among the adult ages from 2050years and Payne et al., ${ }^{26}$ in prison inmates in Dschang, Cameroon due to indiscriminate eating when permitted to go out and work without surveillance. Hookworms infections tend to occur in almost all age groups. This is similar to the reports of Hesham et al., ${ }^{27}$ who suggests that the differences in mode of infection and infectious stages in hookworm as compared to A. lumbricoides and T. trichiura may explain why Hookworm infection tends to occur in older age groups given that most populations of rural communities are embedded in agriculture in which they work barefooted on daily basis.

The prevalence of intestinal helminthiasis varied significantly between the different localities with Bamedji harbouring most of the parasites. This could be attributed to some ecological factors such as temperature, relative humidity and rainfall ${ }^{31}$ which affect the epidemiology of these parasites as well as their social habits, the standard of personal and environmental hygiene.

The current study reported students and farmers with high prevalence of intestinal helminthiasis. This is in agreement with the records of Akinseye et al., ${ }^{20}$ who suggest that the high prevalence of STH among these adolescents could be associated with poverty in the area, poor hygiene and sanitation. Higher percentage of the population lives in mud housing. These people are predominantly farmers using bare hands during farming, depending solely on stream water and uncovered wells for their drinking water, which may be polluted from the source with faecal materials as children defecate in their surrounding environment.

Another important factor is the level of education of individuals. The present study revealed very high prevalence $(28.6 \%)$ in those from the primary level of education. One can conclude that they are ignorant of the dangers that await them when they do not take personal and environmental hygiene into consideration. This calls for the need of an integrated approach that includes education on personal hygiene, improved sanitary and environmental conditions and provisions of portable drinking water which are inevitable measures in achieving a sustainable elimination of these infections ${ }^{20}$.

Multiple helminth infection is a common phenomenon in areas where different types of parasites are encountered. Cases of simple, double and triple infections were observed with respective prevalence of $6.4 \%, 1.8 \%$ and $0.2 \%$ in the total study population. The highest infections were single infections where $2.4 \%, 2.4 \%, 1.5 \%$ and $0.1 \%$ of the total population harboured only $A$. lumbricoides, $T$. trichiura, Hookworm and $C$. hepatica respectively. Three types of double parasitisms were identified with $A$. lumbricoides $+T$. trichiura being the most prevalent $(1.6 \%)$. This is similar to the report of Nougning ${ }^{1}$ which revealed only this association 
with a prevalence rate of $1.58 \%$ and Ngangnang ${ }^{28}$ who recorded a $0.5 \%$ rate for this association in the Littoral Region of Cameroon but different from that of Agbolade et $a l .,{ }^{4}$ who recorded the most prevalent co-infection as that of scariasis + hookworm and Tesfahun and Achenef ${ }^{29}$ who revealed highest double infection in Schistosoma mansoni + A. lumbricoides. This might be due to the fact that both parasites have the same mode of transmission (faeco-oral). The two other associations were those of $A$. lumbricoides + Hookworm which is in line with the results of Akinseye et al., ${ }^{20}$ and C. hepatica + Hookworm with a prevalence of $0.1 \%$ each. Only one triple infection was identified: $A$. lumbricoides $+T$. trichiura + Hookworm. This is in agreement with the report of Agbolade et al., ${ }^{4}$ and Hesham et al., ${ }^{27}$ where $25 \%$ was infected with a combination of trichuriasis, ascariasis and Hookworm infection but different from the combination of $S$. mansoni + A. lumbricoides + Hookworms observed by Tesfahun and Achenef ${ }^{29}$. This is probably due to local endemicity of the study area for these three helminth parasites, free interaction between the host and the contaminated environment and most of all absence of competitive exclusion between the different parasites ${ }^{14}$.

The egg count method as a measure of intensity of intestinal helminth infections, although susceptible to errors of sampling due to periodicity of egg production by female worms and uneven distribution of eggs in faeces, is still widely used ${ }^{30}$. The intensity of helminth infections in this study has been assessed by egg counts where Ascaris lumbricoides (2594.44 \pm 3897.174$)$ showed the highest parasitic-mean intensity and $C$. hepatica $(50 \pm 00)$ the lowest. This was in line with the observations of Maffo tatsinkouet al., ${ }^{14}$. This could be attributed to the fact that Ascaris has a higher egg output $(200,000$ egg per day) compared to Trichuris and hookworm and that C. hepatica is an exceptionally rare infection in humans and where both worms and eggs could not be easily detected in stools of infected hosts. However, the cornerstone of diagnosis still remains the liver biopsy ${ }^{31,32}$. The mean parasitic intensity for each nematode obtained in the present study was lower as compared to that obtained by Wabo Poné et al., ${ }^{11}$. These authors registered $3722 \pm 5677,563 \pm 982$ and $875 \pm 1462$ for A. lumbricoides, T. trichiura and Hookworm respectively.

The categorization of the intensity of infection due to $A$. lumbricoides, T. trichiura, the Hookwormsand $C$. hepatica showed that majority of the sampled population harboured no parasites. However, $77.01 \%$ of infections were light infections. This high rate of light infection is in agreement with the findings of Bethony et al., ${ }^{33}$; Zadock ${ }^{13}$; Megwi ${ }^{34}$ and Maffo tatsinkou et al., ${ }^{14}$ who reported a $100 \%$ light infection. This might be attributed to the method used for egg count per gram of faeces as the Mcmaster technique used in the present study is less sensitive as compared to the Kato Katz technique. This can also be explained by the range of values used for classification; that means in the present study, the classification used by Deuyo ${ }^{35}$ was adopted. Only $A$. lumbricoides had heavy infections. It could be related to the fact that eggs of $A$. lumbricoides can remain viable in the soil for long periods because they are resistant to extremes temperatures than the eggs of other parasites ${ }^{36}$. This is consistent with the findings of Megwi ${ }^{34}$ in the Western Region of Cameroon and WHO ${ }^{37}$ who reported that intestinal parasites are neither evenly nor randomly distributed among hosts, but tend to aggregate in a few heavily infected individuals. All Hookworm infections $(100 \%)$ were light infections. This is probably due to the fact that, most of these infections occurred instead in children as it is known that heavier infections occur during adulthood ${ }^{38,39}$.

\section{Conclusion}

This work showed a relatively low prevalence of gastrointestinal helminths in our study area, a proof of the effectiveness of the national de-worming campaigns but could reach endemic proportions in cases of non- treatment and non respect of sanitary rules. So, it is better to say that prevention is better than cure and health education is one of the key factors to the realization of the Cameroon's vision as an emerging nation by the year 2035 .

\section{References}

[1] Nougning, J. D. (2012). Contribution a l'épidemiology des infestations a Ascaris lumbricoides, Trichuris trichiura et Ankylostomes dans les localités de Bambili et Bambui au Nord-Ouest du Cameroon. Mémoire rédigé et présenté en vue de l'obtention du diplôme de Master of Science en biologie animale, Université de Dschang, Cameroun. 71p.

[2] WHO. (2012). Eliminating soil transmitted helminthiasis as a public health problem in children: Progress report 2001-2010 and strategic plan 2011-2020.

[3] Hoste, H., Jackson, F., Athanasiadou, S., Thamsborg, M. S. and Hoskin, O. S. (2006). The effect of tannin-rich plants on parasitic nematodes in ruminants. Trends parasitol. 22:253261

[4] Agbolade, O. M., Akinboye, D. O. and Awolaja, A. (2004). Intestinal helminthiasis and urinary schistosomiasis in some villages of Ijebu North, Ogun State, Nigeria. African Journal of Bio technology, 3: 206 - 209.

[5] Brooker, S., Archie, C., Don, A. C., Bundy, A. P. (2006). Global epidemiology, Ecology and control of soil transmitted helminth infections. Advances in parasitology, 62: 221-261.

[6] Essogo, A. (2004). Croisade contre les vers intestinaux. www.allafrica.com. p 1.

[7] Benedict, M. M. (2010). The influence of intestinal parasites on academic performance among primary school children in Nairobi province, Kenya. A thesis submitted in partial fulfillment for the award of the degree of Master of Public Health in the School of Health Sciences of Kenyatta University. $128 \mathrm{p}$.

[8] Lontouo, T. M. (2000). Babadjou: un village Bafung, une histoire, un destin. Editions Soulekong L1/ 2000.

[9] Thienpont, D., Rochette, F. \& Vanparijs, O. F. J. (1979). Diagnosing helminthiasis by Coprological Examination. Janssen Research Foundation, Beerse, Belgium, pp.48-67. 
[10] Balen, J., Giovanna, R., Yue-Sheng, L., Zheng-Yuan, Z., LiPing, Y. G., Gail, M. W., Xin-Song, L., Meng-Zhi, S., XinLing, Y., Jurg, U. and Donald, P. M. (2011). Risks factors for helminth infections in a rural and peri-urban setting of the Dongting lake area, People's Republic of China. International Journal for Paraitology, 41: 1165-1173.

[11] Wabo Poné, J., Mpoame, M., Nkeng Efouet, A. P and Bilong, B. C. F. (2012). Prevalence and intensity of infections of three neglected tropical diseases in patients consulted at a Traditional Health Care Centre in Dschang West Cameroon. Tropical Parasitology, 2(1):24-28.

[12] Ephrem, T., Jemal, M. and Habtamu, M. (2015). Intestinal helminthic infections among elementary students of Babile town, Eastern Ethiopia. Pan African Medical Journal, P 20:25

[13] Zadock, D. M. (2012). Soil-transmitted helminths infections, malnutrition and anaemia among primary school children in Same District. Master of Science In Parasitology and Medical Entomology of Muhimbili University of Health and Allied Sciences. 76p.

[14] Maffo Tatsinkou. C. G., Wabo, P. J., Fopa, F. and Mpoame, M. (2015). Gastrointestinal Helminth Infections in HIV Seropositive and Seronegative Patients in Dschang, Cameroon. International Journal of Tropical Diseased Health, 5(4): 245-251.

[15] Mohammed, S., Tadesse, D. and Zewdneh, T. (2015). Prevalence of Intestinal Helminths and Associated Risk Factors in Rural School-Children in Were-Abaye Sub District, Tigray Region, Northern Ethiopia. Parasitologica Globalis, 6 (1): 29-35.

[16] Larry, R. S. (2009). Foundations of Parasitology. McGraw Hill Higher Education.

[17] Maffo, T. C. G. (2013). Coinfection Helminthes GastroIntestinaux et VIH/SIDA dans la Ville de Dschang. Mémoire rédigé et présenté en vue de l'obtention du diplôme de Master of Science en biologie animale, Université de Dschang, Cameroun. 82p.

[18] CDC, (2011) Parasites and Health: Capillariasis". Center for Disease Control. Retrieved 14 September 2011.

[19] Abelau, M., Goselle, O. N., Udeh, E. O., D-Popova, D. D. and Popov, T. V. (2011). A Comparative Study of the Prevalence of helminth arasites in Hiv seropositive and Hiv seronegative individuals In Plateau State, Nigeria. Nigerian Annals of Natural Sciences, 11: 22-32.

[20] Akinseye, J. F., Nmorsi and Akinbolaji, T. J. (2015). Human Soil-Transmitted helminthiasis among adolescents in IlaraMokin Community, Ondo State, Nigeria; A Case Study of Ascarislumbrecoides OPG, Trichuris trichuira and Hookworm. International Journal of Life Sciences Research, 3(1): 108-112p.

[21] Biu, A. A. and Kofur, I. (2010). Prevalence of human gastrointestinal parasites in Biu, Borno state, Nigeria. Animal research international, 7(2): 1223-1225.

[22] Gessessew, B., Berhe, D., Megbaru, A., Haile, D. and Tensay, K. (2015). A survey of intestinal parasitic infections among Dega Ochollo primary school children, Ochollo, South Ethiopia. Science Journal of Public Health, 3(1): 56-60.

[23] Nmor, J. C., Onojafe J. O. and B. A. Omu. (2009). Anthropogenic indices of soil transmitted helminthiasis among children in Delta State, Southern Nigeria. Iranian
Journal of Public Health, 38(3): 31-38.

[24] Seleshi, K., Alemeshet, Y. and Yoseph, M. (2011). Prevalence and Predictors of Intestinal Helminthiasis among School Children in Jimma Zone. Ethiop J Health Sci. 21(3): 75-82.

[25] Susan, E. A. (1998). The Merck Veterinary Manual (8thEdition). White House Stat. N. J Merck Newdelhi India. 85: 1515-1544.

[26] Payne, V. K., Fusi-Ngwa, C. K. and Tanning, K. M. (2013). Common infectious diseases among inmates in Dschang Prison, West Region, Cameroon. The Canadian Journal of infection Control, pp 161-166.

[27] Hesham, M. S. A., Azlin, M., Nor, A. M., Shaikh, A., Sa'iah, A., Fatmah, M. S., Ismail, M. G., Firdaus, M. S. A., Aisah, M. Y., Rozlida, A. R. and Norhayati, M. (2006). Prevalence and distribution of soil-transmitted helminthiasis among orang asli children living in peripheral Selangor, Malaysia. Department of Parasitology and Medical Entomology, Faculty of Medicine, University Kebangsaan Malaysia, Jalan Raja Muda Abdul Aziz, 50300 Kuala Lumpur, Malaysia. Vol 37 No. 1 January 2006.

[28] Ngangnang, G. R. (2013). l'influence de l'âge et du sexe sur la prévalence et l'intensité des helminthiases gastro-intestinales chez les enfants scolarisés de Nkondjock (Littoral Cameroun). Mémoire rédigé et présenté en vue de l'obtention du diplôme de Master of Science en Biologie Animale, Université de Dschang. 60p.

[29] Tesfahun, A. and Achenef, A. (2015). A Survey of SoilTransmitted Helminths Infections and Schistosomiasis mansoni among School Children in Libo-Kemkem District, Northwest Ethiopia: Cross Sectional Study. American Journal of Health Research, 2015; 3(2): 57-62

[30] Croll, N. A., Anderson, R. M., Gyorkos, T. W. and Ghadirian, E. A. (1982). The population biology and control of Ascaris lumbricoides in a rural community in Iran. Trans Royal Society Tropical Medicine and Hygiene, 1982, 76: 187-19.

[31] Li, C. D., Yan, H. L. and Wang, Y. (2010). Capillaria hepatica in China. World J. Gastroentero. 16(6):698-702.

[32] Sindhu, S., Toma, E., Cordeiro P., Ahmad R., Morisset R. (2006). Relationship of in-vivo and ex-vivo levels of Th1 and Th2 cytokines with viremia in HAART patients with and without opportunistic infections. J. Med. Virol.78:431-439.

[33] Bethony, J., Brooker, S., Albonico, M., Stefan, M., Alex, L., David, D. and Hotez, P. J. (2006). Soil -transmitted helminth infections: ascariasis, trichuriasis, and hookworm. Lancet, 367: $1521-1532$.

[34] Megwi, L. (2013). Evaluation of the efficacy of albendazole, mebendazole and ivermectine on Geohelminths amongstschool age children in Bafoussam. Thesis submitted in partial fulfillment for the award of a Masters degree in University of Dschang. 86p.

[35] Deuyo, F. O. (1997). Prévalence de certains nématodes gastrointestinaux dans la population scolaire de la ville de Dschang. Mémoire rédigé et présenté en vue de l'obtention du diplôme de Master of Science en Biologie Animale, Université de Dschang, Cameroun.

[36] Bundy, D. A. P. and Cooper, E. S. (1989). Trichuris and trichuriasis in humans. Advances in Parasitology, 28: 107173. 
[37] World Health Organization, (2002). Prevention and control of schistosomiasis and Soil-transmitted helminthiasis, WHO technical report series, 912, Geneva, Switzerland.

[38] Anderson, R. M. and May, R. M. (1991). Infectious diseases of Humans: dynamics and control. Oxford: Oxford University press, $757 \mathrm{p}$.
[39] Bundy, D. A. P. (1995). Epidemiology and transmission of intestinal helminths. In: Farthing MJG, Keusch GT, Wakelin D. (eds) Enteric Infection 2. Intestinal helminths. London: Chapman Sc Hall. P 5-24. 